\title{
DAVID GEORGE KENDALL AND APPLIED PROBABILITY
}

David George Kendall, described as 'the father of British probability' in obituaries in The Independent, 1 November 2007, and in The Times, 21 November 2007, died on 23 October 2007 after a decade of declining health. A more rounded appreciation of his contributions to learning will in due course appear in the Biographical Memoirs of Fellows of the Royal Society, for he was elected a Fellow of the Royal Society in 1964 and served on its Council in 1967-69 and 1983-84. These notes record his particular contributions to the activities of the Applied Probability Trust and attempt to survey some aspects of his work in the field of applied probability more generally.

Indeed, it was in the applied probability field, broadly interpreted, that David Kendall played a pre-eminent role as an exemplar, mentor, and organiser for over 50 years of his active public life that built on his being called into wartime service in March 1940. Much of this can be gleaned from the quasi autobiographical A conversation with David Kendall [2], especially of his formative years in Ripon where he was born (15 January 1918) and schooled, his undergraduate days in Oxford, and most importantly his experiences in operations research during and after World War II when inter alia he was given a week to learn statistics from Frank Anscombe, who used his notes from Maurice Bartlett's Cambridge lectures. Much of his effort during the war was concerned with aspects of rocketry, and innumerable reports were written, presumably (from his conversation with Bingham) on sundry numerical applications, while his spare time was given over to pondering more mathematical matters.

Yet for all this and his avid reading in diverse mathematical topics, David will eventually be remembered as an applied mathematician in the fullest sense. From his initial drive to become an astronomer and therefore first to become a mathematician, it was ultimately the will to exploit whatever could be learnt from mathematical modelling of a particular phenomenon that was the characteristic feature of his work, whether of a population (birth-death or branching processes or epidemics), or organization (queueing theory), or of data (archaeology or seriation), or animal behaviour (bird navigation), to mention just some subjects to which he contributed. As The Times obituarist observed,

His mentor Bartlett had been a master of the informal approach to probability, impatient of formal proofs and mathematical rigour. Kendall could match him in heuristic reasoning, but was much happier if he could fit his calculations into a firm mathematical context. Paradoxically, his scholarly and sometimes pedantic approach made him easier to understand than Bartlett, because the reader could follow the logical argument step by step.

David played a critical role in the start of the Applied Probability Trust and the Journal of Applied Probability (JAP). Joe Gani described it thus (private communication):

In 1963, I attempted to get some support for JAP from the Australian Mathematical Society, the Statistical Society of Australia, and the Australian Academy of Science. Ted Hannan, Norma McArthur and I had raised half the funds necessary to run JAP for a year, even if not a single copy was sold, but we felt we needed more. David Kendall, who had agreed to be one of the journal's editors, got in touch with me and suggested I approach the London Mathematical Society (LMS); I met their Council and managed to convince them that JAP was a feasible enterprise. The LMS Treasurer at that time was Sir Edward Collingwood, 
and he was very helpful: the LMS provided a sum equal to that collected by Ted, Norma and me. We were the first three private Trustees; Collingwood became the fourth Trustee, representing the LMS. We were able to launch JAP successfully in 1964; without David Kendall's advice and support, this would not have been possible.

In the ensuing decade or so, David was active with Jerzy Neyman and the International Statistical Institute (ISI), in establishing and guiding the International Association for Statistics in Physical Sciences (IASPS) as a section of the ISI, reflecting their joint interest in applied probability. In 1973 the IASPS evolved into the Bernoulli Society, an autonomous section of the ISI, of which David was the Founding President. Objects of the Society include 'the advancement, through international contacts, of the sciences of probability (including the theory of stochastic processes) and mathematical statistics and of their applications ....'

David was also a Foundation Editor of Advances in Applied Probability (AAP), and remained an Editor of both $J A P$ and $A A P$ until March 2000. As an Associate Editor of Biometrika in the 1960s, he trained some of his research students in the art of refereeing by giving them simpler and then more demanding tasks. He was an active Editor of the Wiley Series in Probability and Statistics for about 30 years from 1965. He was also an Associate Editor of several other journals, notably Zeitschrift für Wahrscheinlichkeitstheorie from its inception and others of a more applied nature or with some quirky flavour in their publication aims.

David's publications (Mathematical Reviews lists 116 of them) are characterized by his lucid expository style. John Riordan reviewed his two best-known papers in queueing theory [6], [7], describing the former as an 'expository article [that includes] the approach and terminology of Feller's work on recurrent events and Markov chains (Feller, 1949) [and whose] discussion emphasizes [that] the material has numerous applications'. The latter, whose very title stresses this Markov chain aspect ('the method of an imbedded Markov chain, broached in a preceding paper, is clarified and extended'), is the source of the now familiar notation GI/G/1 (general independent input/general service time/1 server) as a shorthand for describing queueing systems. Others have extended the notation in various ways. (One of us has long thought that $k$ is the preferred symbol for the number of servers in a queueing system, because then $D / G / k$ is shorthand for one of the systems so described.) David's interest in queueing stemmed from problems associated with the air lift to Berlin during its blockade in 1948-49. He subsequently wrote a survey paper [10] stressing relevant mathematical developments in the interim period. The power inherent in exploiting regeneration points in studying certain queueing systems, and so extracting, for example, limit properties from just partial analysis of the system, became a standard method in the queueing literature, long before the advent of Palm theory for marked point processes, which is a natural setting for the methodology. Embedded Markov chain analysis is indeed more widely useful than merely in queueing applications.

Just as his papers were beautifully written, so too his lectures were superbly crafted, whether for an undergraduate or research audience, and they were then delivered so as to entrance the listener. Indeed, as a colleague remarked after a seminar that David gave on Delphic semigroup theory at the opening of the Mathematical Institute in Oxford, his exposition made his contributions seem so elementary as almost to obscure their depth and originality.

Many of David Kendall's basic papers have a significant review component in them, for he had the ability to cobble together threads from a range of others' work and weave the ideas into a coherent story. These papers originate in David's 'fascination with capturing an applied problem that has both intrinsic interest and an aspect of intangibility' [22].

Two years before David read his queueing paper to the Royal Statistical Society (RSS), each of Maurice Bartlett, Joe Moyal, and David Kendall wrote papers in a landmark RSS Symposium 
on Stochastic Processes whose proceedings were published both in the Journal and separately. Peter Whittle [22] wrote of his copy as

one of the most tattered volumes on my bookshelf ... [consisting of] three substantial and highly personal survey articles [that] provided magnificent reading and reference at a time when the stochastic process literature was a meagre scattered one. ... [These papers] confirmed, if they did not indeed found, the recognisable British tradition in stochastic processes.

David's contribution here (see [5]) was to the analysis of linear birth and death processes, pursuing in considerable depth a topic begun in [4] and continued with his mentor Maurice Bartlett in [1]. Generating functionals (and, simpler, generating functions) were tools he exploited on a more practical level than his work of a few years later with Reuter on continuoustime Markov processes on a countable state space, for which both authors are properly renowned. Still at the practical level he worked also on epidemic modelling problems [8], [9], [11], relating both probabilistic solutions to precisely defined stochastic models and the more accessible deterministic approximations that come from moment equations.

A few years later when the London Mathematical Society was celebrating its centenary, he turned his attention to a brief survey [12] of Galton-Watson branching processes, blending biography, bibliography, and history before describing new results for a linear pure-birth process conditioned on its asymptotic growth rate. Another note [13] written about the same time gives a corresponding analysis for the supercritical Galton-Watson process, using a direct approach just before definitive accounts of quasistationarity became available.

David Kendall was a more than generous supervisor in suggesting problems that were substantial, more often than not coming with some applied motivation. His students, among whom both of us have the privilege of being counted, were left to publish in their own name, albeit with much helpful guidance. Their efforts comprise a significant component of the work of the 'British school' of stochastic analysis in the decade or two up to around 1970 as reviewed in a marvellous survey paper [14] that David wrote and published as an introduction to the volume on Stochastic Analysis. The introduction [15] in the companion volume on Stochastic Geometry is a much briefer exposition of a subject then in its mathematical infancy.

One of David's friends from both the war years and his Oxford days was the ornithologist David Lack. He died in 1973, and David thought 'it would be nice if I could write something about birds ..., and the mathematics of bird navigation ought to be an interesting topic'. Literature existed on the home-seeking behaviour of birds like the Manx Shearwater which are able to fly across the Atlantic to a small target area off the Welsh coast after being released from an unfamiliar location in north-east USA. So David postulated various models and investigated them both by computer simulation and (where possible) mathematical analysis. The resulting paper stimulated further analysis by Harry Reuter and David Williams in the discussion.

From stochastic geometry, it is a small step to consider questions about the collinearity of points (or its complement, the shape of triangles), and then to move on to questions of shape in higher dimensions (cf. [17]). Such questions became David's preoccupation as he headed into his retirement years. This included writing with his elder son Wilfrid [19] and many other papers that culminated in the four-authored book [20].

In view of our concentration on one particular aspect of David Kendall's work-and even in this we have not been exhaustive-it seems proper to draw attention here to the broader obituary notices in the English press and the forthcoming Memoir of Fellows of the Royal Society (see above), and four papers listed in the references. Paramount amongst these is [2], which is all the more valuable for being a transcription, largely verbatim, of an interview conducted with 
David in January 1994. Volume 45 (2008) of the annual Churchill Review contains written versions of some of the testimonies given at a reception in Churchill College on 7th March 2008 immediately following the Service of Thanksgiving in Great St. Mary's attended by about 250 of David Kendall's family, friends, and colleagues. Many papers in the festschrift edited by Kingman and Reuter [21] contain comments on various aspects of David's work and interests. The introduction in [16] includes details of his collaboration with Reuter, on which topic the description in [2] is largely complementary. Scattered through this conversation are references to interaction with John Hammersley, and this in turn is complemented in [18].

David Kendall was an energetic and generous man of extraordinary talent: applied probability and statistics are much the richer for his endeavours and insights.

Australian National University

D. J. DALEY

Victoria University of Wellington

D. VERE-JONES

\section{References}

[1] Bartlett, M. S. And Kendall, D. G. (1951). On the use of the characteristic functional in the analysis of some stochastic processes occurring in physics and biology. Proc. Camb. Philos. Soc. 47, 65-76.

[2] Bingham, N. H. (1996). A conversation with David Kendall. Statist. Sci. 11, 159-188.

[3] Feller, W. (1949). Fluctuation theory of recurrent events. Trans. Amer. Math. Soc. 67, 98-119.

[4] Kendall, D. G. (1948). On the generalized 'birth-and-death' process. Ann. Math. Statist. 19, 1-15.

[5] Kendall, D. G. (1949). Stochastic processes and population growth. J. R. Statist. Soc. Ser. B 11, 230-264.

[6] Kendall, D. G. (1951). Some problems in the theory of queues. J. R. Statist. Soc. Ser. B 13, 151-173; discussion $173-185$.

[7] Kendall, D. G. (1953). Stochastic processes occurring in the theory of queues and their analysis by the method of the imbedded Markov chain. Ann. Math. Statist. 24, 338-354.

[8] Kendall, D. G. (1956). Deterministic and stochastic epidemics in closed populations. In Proc. Third Berkeley Symp. Math. Statist. Prob., 1954-1955, Vol. IV, University of California Press, pp. 149-165.

[9] Kendall, D. G. (1957). La propagation d'une épidémie ou d'un bruit dans une population limitée. Publ. Inst. Statist. Univ. Paris 6, 307-311.

[10] Kendall, D. G. (1964). Some recent work and further problems in the theory of queues. Teor. Veroyat. Primen. 9, 3-15.

[11] Kendall, D. G. (1965). Mathematical models for the spread of infection. In Mathematics and Computer Science in Biology and Medicine, HMSO, London, pp. 213-225.

[12] Kendall, D. G. (1966). Branching processes since 1873. J. London Math. Soc. 41, 386-406.

[13] Kendall, D. G. (1966). On super-critical branching processes with a positive chance of extinction. In Research Papers in Statistics (Festschrift J. Neyman), John Wiley, London, pp. 157-165.

[14] Kendall, D. G. (1974). An introduction to stochastic analysis. In Stochastic Analysis, eds D. G. Kendall and E. J. Harding, John Wiley, London, pp. 3-43.

[15] Kendall, D. G. (1974). An introduction to stochastic geometry. In Stochastic Geometry, eds E. J. Harding and D. G. Kendall, John Wiley, London, pp. 3-9.

[16] Kendall, D. G. (ed.) (1986). Analytic and Geometric Stochastics (Papers in honour of G. E. H. Reuter). Special supplement to Adv. Appl. Prob. 19.

[17] Kendall, D. G. (1988). Applied probability—past, present and future. In A Celebration of Applied Probability (J. Appl. Prob. 25A), ed. J. Gani, Applied Probability Trust, Sheffield, pp. 25-30.

[18] Kendall, D. G. (1990). Speech proposing the toast to John Hammersley - 1 October 1987. In Disorder in Physical Systems: A Volume in Honour of John M. Hammersley on the Occasion of His 70th Birthday, eds G. R. Grimmett and D. J. A. Welsh, Oxford University Press, pp. 1-3.

[19] Kendall, D. G. and Kendall, W. S. (1980). Alignments in two-dimensional random sets of points. Adv. Appl. Prob. 12, 380-424.

[20] Kendall, D. G., Barden, D., Carne, T. K. and Le, H. (1999). Shape and Shape Theory. John Wiley, Chichester.

[21] Kingman, J. F. C. And Reuter, G. E. H. (eds) (1983). Probability, Statistics and Analysis (London Math. Soc. Lecture Notes 79). Cambridge University Press.

[22] Whittle, P. (1983). Competition and bottle-necks. In Probability, Statistics and Analysis (London Math. Soc. Lecture Notes 79), eds J. F. C. Kingman and G. E. H. Reuter, Cambridge University Press, pp. 277-284. 